\title{
Fungal Glucosamine: Production, Purification, and Characterization
}

\author{
M. Soltani ${ }^{\text {a }}$, K. Karimi ${ }^{\text {a }}$, A. Zamani ${ }^{\text {b }}$ \\ ${ }^{a}$ Department of Chemical Engineering, Isfahan University of Technology, Isfahan, Iran \\ ${ }^{\mathrm{b}}$ Swedish Centre for Resource Recovery, University of Borås, 50190 Borås, Sweden \\ akram.zamani@hb.se
}

\begin{abstract}
A novel method was developed for production, recovery, and purification of fungal glucosamine. Fungal glucosamine is a good candidate for replacement of glucosamine obtained from shellfish wastes. Mycelium of the Rhizopusoryzae was treated with hot sodium hydroxide solution to obtain the fungal cell wall skeleton. Phosphates were removed from the cell wall by cold dilute sulfuric acid treatment. Phosphate free cell wall, containing mainly chitin and chitosan, was hydrolyzed by hydrochloric acid to produce glucosamine. The dissolved glucosamine was recovered from acid solution through a cold filtration step followed by an acid evaporation. The crude glucosamine was purified through dissolution in distilled water, decolorization, and evaporation stages. The obtained glucosamine crystals demonstrated high purity according to FTIR and DTA analyses. The yield of glucosamine was also optimized changing the acid concentration, reaction temperature, and time. Acid concentration, as well as the acid concentration-temperature and temperature-time interactions exhibited the most significant effects on glucosamine yield. The optimal temperature, time, and acid concentration giving the highest product yield were $70^{\circ} \mathrm{C}, 3.5 \mathrm{~h}$, and $12 \mathrm{M}$ (or $110^{\circ} \mathrm{C}, 6 \mathrm{~h}$, and $6 \mathrm{M}$ ), respectively. At these conditions $0.52 \mathrm{~g}$ pure glucosamine was obtained from each gram of the fungal cell wall. This corresponds to $90.7 \%$ of theoretical yield which could be obtained by hydrolysis of the chitin and chitosan present in the cell wall of $R$. oryzae.
\end{abstract}

Keywords: Chitin; Chitosan; Glucosamine hydrochloride; Hydrolysis, Purification; Rhizopusoryzae Abbreviations: AIM-Alkali Insoluble Materials, PFAIM- Phosphate Free Alkali Insoluble Material

\section{INTRODUCTION}

Glucosamine hydrochloride is a white crystal, odorless, and water soluble amino monosaccharide. This is the precursor of the proteoglycans in the joints, skin, nails, and heart valves, but mostly found in the synovial fluid and has an important role in cartilage resilience and joint lubrication (Asamoah 2008). As the body ages, its ability to synthesis the glucosamine reduces. This leads to stiffness, inflammation, and joint erosion which causes a pain known as arthritis in back, knees, and neck(Cao et al. 2008). Glucosamine can relief the pain and assist in rehabilitation of cartilage and refreshes of synovial fluid (Mojarrad and Nemati 2007; Nakamura 2011).

Glucosamine is the constituent of chitin and chitosan, second abundant non-toxic, biodegradable, and biocompatible biopolymers after cellulose (Nydert et al. 2008; Yan and Evenocheck 2012; Zamani et al. 2008). Chitin and chitosan have extensive applications in biotechnology, medicine, and agriculture (Abdou et al. 2008; Flocco and Giulietti 2003; Luan et al. 2005; Park and Kim 2010; Yang 2011)and currently are mainly produced from shellfish marine wastes(Manni et al. 2010; Zamani 2010).

Glucosamine can be produced from chitin and chitosan through chemical or enzymatic hydrolysis. Enzymatic hydrolysis has major limitations of high cost of enzyme, enzyme instability, and incomplete hydrolysis to monomeric glucosamine (Liu et al. 2013). In chemical approach, in the presence of concentrated hydrochloric acid, two acid-catalyzed reactions, i.e., depolymerization and deacetylation of chitin and chitosan, take place which convert these polymers to glucosamine hydrochloride (Islam and Masum 2011).Several factors including acid concentration, acid to chitin (or chitosan) ratio, reaction temperature, and reaction time affect the yield of glucosamine hydrochloride(Ajavakom et al. 2012; Mojarrad and Nemati 2007; Yan and Evenocheck 2012).

Mojarrad et al. reported an optimum condition for glucosamine preparation from chitin at $100^{\circ} \mathrm{Cusing}$ 37\% hydrochloric acid, 9:1 $\frac{\mathrm{ml} \text { acid }}{\text { gr chitin }}$ and $4 \mathrm{~h}$ hydrolysis (Mojarrad and Nemati 2007).In another study 
the highest glucosamine yield from chitin was obtained using 37\% hydrochloric acid at $20: 1\left(\frac{\mathrm{ml}}{\mathrm{gr}}\right)$ acid to solid ratio at $90^{\circ} \mathrm{Cfor} 1.30 \mathrm{~h}$ (Islam and Masum 2011). Ajavacom et al.(Ajavakom et al. 2012) achieved $57 \%$ yield by hydrolyzing chitin under microwave heating using $38 \%$ pre-warmed hydrochloric acid under reflux condition for just 12 minutes. They also used sonication pretreatment to enhance the glucosamine yield to $62 \%$.

Marine source of glucosamine has different drawbacks e.g. variations in composition under uncontrolled growth, seasonal and location dependency, heavy metal poisoning duo to contaminated oceans, and shellfish allergy for some of people (Bohlmann et al. 2004; Hsieh et al. 2007; Sitanggang et al. 2012; Zhang et al. 2012).

Glucosamine is also available as chitin and chitosan in cell wall of some fungi including Zygomycetes and Ascomycetes.(Asamoah 2008; Kim et al. 2001; Mohammadi et al. 2013; Zamani 2010). Some strains of Zygomycetes fungi e.g., Rhizopusoryzaeand Mucorindicus, are non-pathogenic filamentous fungi that can grow on a notable diversity of substrates containing several harsh inhibitors e.g., lignocellulosic hydrolysates (Karimi et al. 2005; Karimi and Zamani 2013; Zamani 2010). In addition to high ethanol yield, the biomass of these fungi as a by-product has been proposed to be used as a source of chitosan and protein for the production of e.g., superabsorbent polymers (Zamani 2010), fish feed(Edebo 2003; Karimi and Zamani 2013), and a replacement for yeast extract, after fungal autolysis (Karimi and Zamani 2013).

Measurement of glucosamine content in the form of chitin and chitosan in some strains of Ascomycetes and Zygomycetes has been performed before (Bohlmann et al. 2004; Mohammadi et al. 2012; Sitanggang et al. 2012; Sitanggang et al. 2009; Zhang et al. 2012).However, to our knowledge there is no report on production, purification, and characterization of fungal glucosamine. The main goal of this research was to develop an efficient method for preparation and purification of fungal glucosamine. The obtained fungal glucosamine was characterized using FTIR and DTA analysis. Furthermore, different parameters affecting the yield of fungal glucosamine, during the course of hydrolysis reaction were identified and optimized.

\section{MATERIALS AND METHODS}

\subsection{Microorganism}

The biomass of Rhizopusoryzae, CCUG 28958, grown on spent sulfite liquor from a paper pulp industry, was kindly provided by Prof. Lars Edebo, University of Göteborg.

\subsection{Protein Removal from Biomass}

In order to remove the proteins and lipids from biomass, $30 \mathrm{~mL}$ of sodium hydroxide $(0.5 \mathrm{M})$ was added to each gram of biomass and the mixture was autoclaved at $121{ }^{\circ} \mathrm{C}$ for $20 \mathrm{~min}$. After cooling to room temperature, the Alkali Insoluble Material (AIM) was separated by centrifugation (4000 rpm, 5 min), washed with distilled water until neutralization and freeze-dried(Mohammadi et al. 2012).

\subsection{Phosphate Removal from AIM}

In order to remove phosphate portion, the AIM was treated with $0.05 \mathrm{M}$ sulfuric acid solution (100 $\mathrm{mL}$ solution per gram dried AIM) at room temperature for $30 \mathrm{~min}$. The residual portion was separated by centrifugation, washed with distilled water until neutral $\mathrm{pH}$, and then freeze-dried (Naghdi et al. 2014).

\subsection{Preparation of Glucosamine Hydrochloride}

The Phosphate Free Alkali Insoluble Material (PFAIM) (0.5 g) was powdered using a kitchen mill and then treated with $75 \mathrm{ml}$ of hydrochloric acid $(6-12 \mathrm{M})$ at different temperatures $\left(70-110{ }^{\circ} \mathrm{C}\right)$ for 1-6 h. The reaction took place in $100 \mathrm{ml}$ sealed glass bottlesin an oil bath. After termination of reaction and cooling to room temperature, the unreacted portion was filtered and discarded, and the clear solution was poured into a glass Petri-dish and left under a laminar air flow fume hood for evaporation of acid. For recovery of crude glucosamine, the remained brownish crystal was washed with ethanol, separated from the plate, filtered, and dried in an oven at $55^{\circ} \mathrm{C}$.

\subsection{Purification of Glucosamine Hydrochloride}

Each gram of crude glucosamine was dissolved in $10 \mathrm{ml}$ de-ionized water and decolorized with approximately $0.2 \mathrm{~g}$ activated charcoal and heated at $55^{\circ} \mathrm{C}$ for $1 \mathrm{~h}$. Afterdecolorization, the impurities 
and carbon were removed by filtration using a filter paper (What man No 40). The clear glucosamine solution was evaporated under the hood to get pure fungal glucosamine crystals.

\subsection{Determination of Glucosamine and $\mathbf{N}$-acetyl Glucosamine Content of AIM and its Derivatives}

The glucosamine and $\mathrm{N}$-acetyl glucosamine were quantified by sulfuric acid hydrolysis of AIM according to the method developed by Mohammadi et. al. (Mohammadi et al. 2012). In brief, AIM was hydrolyzed by sulfuric acid and nitrous acid and the released acetic acid and 2,5-anhydromannoe were analyzed.

\subsection{Determination of Protein Content of Biomass and its Derivatives}

The protein content of biomass and its derivatives was measured according to the Biuret method(Verduyn et al. 1990) with minor modifications. Accordingly, $10 \mathrm{mg}$ of samples were mixed with $3 \mathrm{ml} \mathrm{NaOH}$ solution $(1 \mathrm{M})$ at room temperature for $2 \mathrm{~h}$. Then, the samples were placed in boiling water for $10 \mathrm{~min}$ and then immediately cooled to room temperature in an ice bath. After cooling, $1 \mathrm{ml}$ of $2.5 \% \mathrm{CuSO}_{4} .5 \mathrm{H}_{2} \mathrm{O}$ solution was added and mixed for $5 \mathrm{~min}$. The obtained suspension was centrifuged at $4000 \mathrm{rpm}$ for $5 \mathrm{~min}$, and the absorbance of the supernatant was measured at $555 \mathrm{~nm}$.

\subsection{Determination Phosphate Content}

Determination of phosphate content of cell wall derivatives was done using ammonium molybdate spectrometric method (Zamani 2010). Briefly, the samples were mixed with ascorbic acid and molibdate reagents and the absorbance was measured at $880 \mathrm{~nm}$.

\subsection{Characterization of Prepared Glucosamine}

FTIR spectra of glucosamine samples were conducted on a Bruker (Bruker, tensor 27) spectrophotometer with $4 \mathrm{~cm}^{-1}$ resolution and $600-4000 \mathrm{~cm}^{-1}$ scanning range. The melting point of glucosamine was estimated by STA/TGA method (Bahr, 503, Germany).

\subsection{Experimental Design and Statistical Analysis}

The performed design was a three parameter Box-Behnken design with three levels for each factor. Independent factors were acid concentration $\left(\mathrm{X}_{1}, \mathrm{M}\right)$, temperature $\left(\mathrm{X}_{2},{ }^{\circ} \mathrm{C}\right)$, and reaction time $\left(\mathrm{X}_{3}, \mathrm{~h}\right)$. After preliminary experiments (data not shown), the acid to FPAIM was chosen as $150 \mathrm{ml} / \mathrm{g}$ for all experiments. The actual values for independent factors are shown in Table 1.

Table1. The actual values for independent factors in RSM

\begin{tabular}{|c|l|l|l|l|}
\hline Factor & Name & Low value & Mid-value & High value \\
\hline$X_{1}$ & Acid concentration $(\mathrm{M})$ & 6 & 9 & 12 \\
\hline$X_{2}$ & Temperature $\left({ }^{\circ} \mathrm{C}\right)$ & 70 & 90 & 110 \\
\hline$X_{3}$ & Time $(\mathrm{h})$ & 1 & 3.5 & 6 \\
\hline
\end{tabular}

By using Response surface Methodology in the form of Box-Behnken method, fifteen experiments were carried out. All experiments were conducted in duplicate (thirty experiments in total).

The glucosamine yield was predicted using the second order polynomial as a function of three independent factors, quadratic terms, and their interactions as:

$y=\beta_{0}+\beta_{1} X_{1}+\beta_{2} X_{2}+\beta_{3} X_{3}+\beta_{11} X_{1}^{2}+\beta_{22} X_{2}^{2}+\beta_{33} X_{3}^{2}+\beta_{12} X_{1} X_{2}+\beta_{13} X_{1} X_{3}+\beta_{23} X_{2} X_{3}$

In this equation, $\beta_{0}, \beta_{i}, \beta_{i i}$, and $\beta_{i j}$ represent constant, linear, quadratic, and interaction regression coefficients, respectively. The results were analyzed by considering analysis of variance (ANOVA), coefficient of determination $\left(R^{2}\right)$, and response's Surface plots, which were achieved in addition to regression coefficients, using Minitab version 16 (Minitab Inc., USA).

\section{RESULTS AND DiSCUSSION}

The fungal biomass has been used for production of various products e.g. fungal chitosan, superabsorbent polymers, and fish feed (Zamani 2010). In this work, a simple method for production, recovery and purification of glucosamine was developed. The cell wall of the zygomycetes fungi has considerable amounts of proteins, lipids, and phosphates (Zamani et al. 2010). These impurities must be removed before hydrolyzing the chitin and chitosan portions in the cell wall. For preparation of cell wall skeleton containing chitin and chitosan, first, protein and lipid impurities were removed via hot 
alkali pretreatment (Yaghobi 2012; Zamani 2010). The yield of AIM was $0.15 \mathrm{~g} / \mathrm{g}$ biomass. Then, the resulting AIM was subjected to cold, dilute sulfuric acid pretreatment for phosphate removal (Naghdi et al. 2014). The yield of PFAIM was $0.79 \mathrm{~g} / \mathrm{g}$ AIM. The Glucosamine, N-acetyl glucosamine, protein, and phosphate content of PFAIM were 33.1, 24.8, 2.0, and 3.0 \% respectively. PFAIM was hydrolyzed using hydrochloric acid to form glucosamine via deacetylation and depolymerization of chitin and chitosan. The prepared glucosamine was subsequently recovered and purified.

\subsection{Recovery of Glucosamine from Acid}

The dried PFAIM was subjected to depolymerization and deacetylation using concentrated hydrochloric acid (37\%). Prior to any optimization of the hydrolysis reaction it was necessary to recover the glucosamine from the acid solution.

Different methods have been proposed for recovery of glucosamine after hydrolysis of shellfish chitin and chitosan. In this study, these methods were tested for recovery of fungal glucosamine.

Islam et al. (Islam and Masum 2011), Cao et al. (Cao et al. 2008), and Sibi et al.(Sibi et al. 2013) claimed that the insoluble fraction of shellfish chitin after acid hydrolysis is glucosamine. Accordingly, the mixture of PFAIM after the hydrolysis step was filtered while it was still hot. Then, the black filter cake was collected, dried, and mixed with water, but it was not soluble in water. Since glucosamine is water soluble, it was concluded that the filter cake was not glucosamine. Additionally, filtration of the mixture after cooling to room temperature did not improve the solubility of the obtained black filter cake.

Pan et al. (Pan et al. 2011) and Sitanggang (Sitanggang 2009) suggested concentration of the hydrolysis mixture by evaporation to about $50 \%$ of the initial volume and subsequent additional of ethanol for precipitation of glucosamine (Pan et al. 2011; Sitanggang 2009). Applying this method on fungal glucosamine hydrolysate did not end with any glucosamine precipitation.

Complete evaporation of the acid to achieve crude glucosamine hydrochloride crystals has been also suggested for shellfish glucosamine (Dolgopyatova et al. 2011; Xavier 2006). Applying the heat during the course of evaporation however, may lead to destruction of glucosamine (Yan and Evenocheck 2012). Therefore, in this work fungal glucosamine solution was poured into glass Petridishes and left under a fume hood with a laminar air flow. The acid was completely evaporated in 24 $\mathrm{h}$ and the crystals of crude glucosamine were left. Therefore, the evaporation method was used for recovery of fungal glucosamine. The crude glucosamine was removed from the Petri-dish surface using ethanol. This was dried at $55^{\circ} \mathrm{C}$ and purified by dissolution in water and color removal by activated charcoal. A clear aqueous glucosamine solution was achieved after filtration. This solution was evaporated until dryness at room temperature and pure white fungal glucosamine crystals were obtained. A flow-diagram of the fungal glucosamine purification is presented Figure 1.

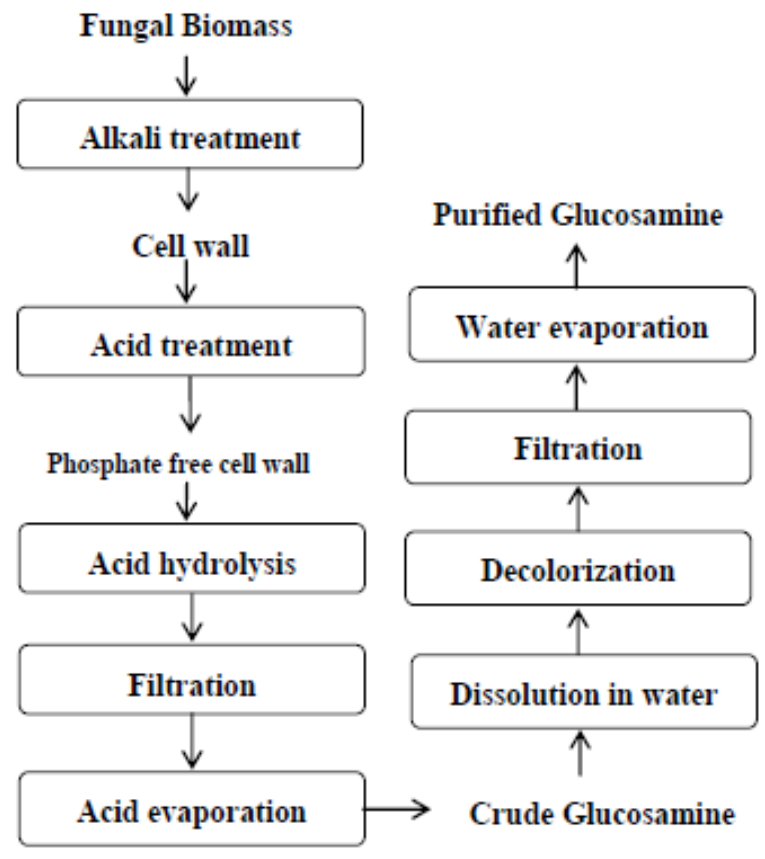

Figure1. Flow diagram of the method for production and purification of fungal glucosamine 


\subsection{Characterization of Glucosamine}

Purity of the obtained fungal glucosamine was investigated and compared with a pure commercially available glucosamine (from Sigma-Aldrich).

Consistency of the FTIR spectrum of fungal glucosamine with that of reference glucosamine (Figure 2) confirms its high purity.

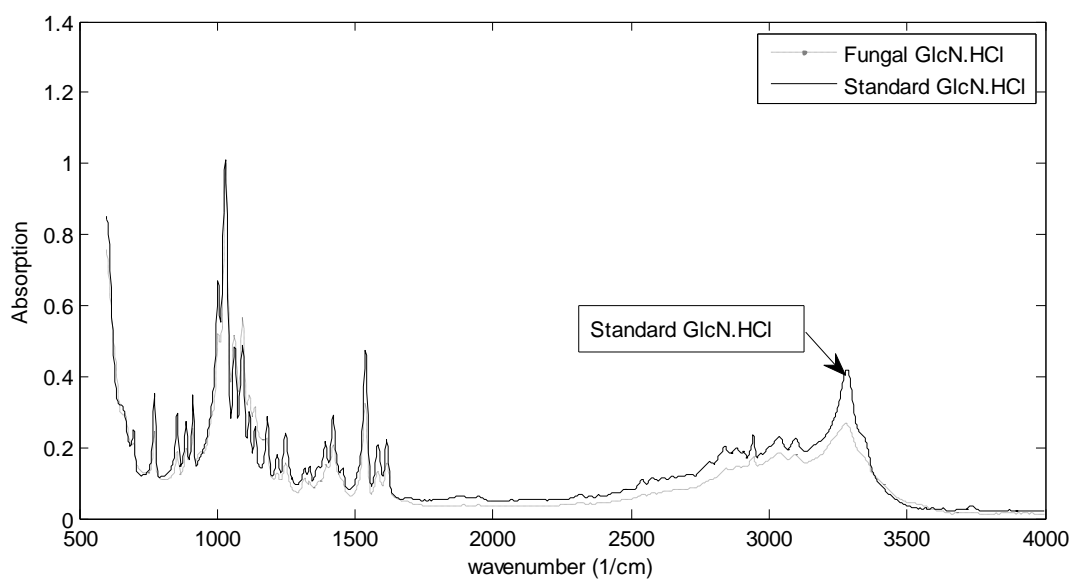

Figure2. FTIR spectra of standard and fungal glucosamine

DTA analysis (Figure3) forecasted a melting point for the reference glucosamine and fungal glucosamine at $194{ }^{\circ} \mathrm{C}$ and $187^{\circ} \mathrm{C}$, respectively. Both values are close to the range reported for pure glucosamine (Mojarrad and Nemati 2007).

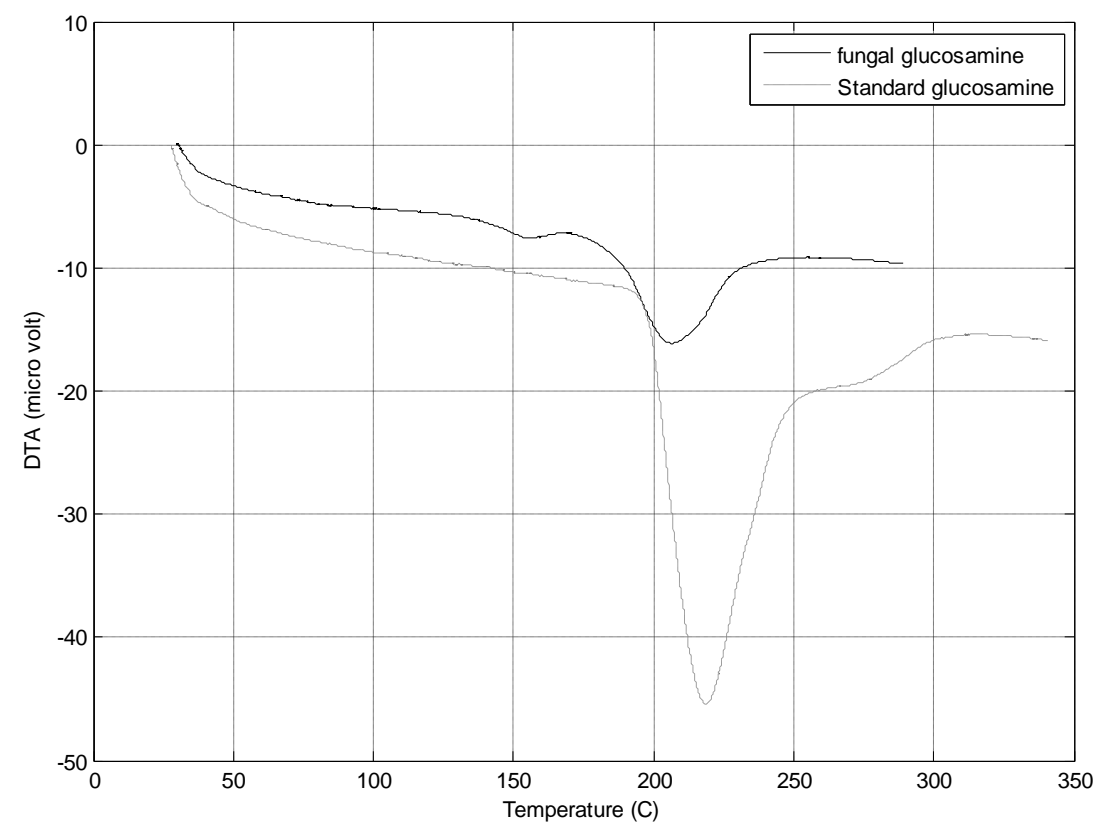

Figure3. DTA curves for the standard and fungal glucosamine

\subsection{Optimization of Glucosamine Yield}

The yield of glucosamine obtained from shellfish chitin and chitosan depends on several factors including acid concentration, temperature, and hydrolysis time (Mojarrad and Nemati 2007; Xavier 2006; Yan and Evenocheck 2012). Based on previous reports for chitin and chitosan hydrolysis (Mojarrad and Nemati 2007; Sibi et al. 2013;Yan and Evenocheck 2012) acid concentration, temperature, and time were selected in the range of 6-12 M, 70-110 ${ }^{\circ} \mathrm{C}$, and 1-6 h, respectively. Based on Box-Behnkendesign, 30 runs were conducted. The average yields of fungal glucosamine (Obtained yield) are given in Table 2, in addition to predicted results from the regression analysis (Predicted yield). 


\section{Soltani et al.}

Table2. Glucosamine yield (real and predicted) at different hydrolysis condition

\begin{tabular}{|l|l|l|l|l|l|}
\hline Run & Acid concentration $(\mathrm{M})$ & Temperature $\left({ }^{\circ} \mathrm{C}\right)$ & Time $(\mathrm{h})$ & Obtained yield $(\%)$ & Predicted yield $(\%)$ \\
\hline 1 & 6 & 70 & 3.5 & $8.2 \pm 3.3$ & 3.3 \\
\hline 2 & 6 & 90 & 1 & $21.2 \pm 1.0$ & 25.1 \\
\hline 3 & 6 & 90 & 6 & $37.7 \pm 1.0$ & 39.9 \\
\hline 4 & 6 & 110 & 3.5 & $43.1 \pm 2.9$ & 41.8 \\
\hline 5 & 9 & 70 & 1 & $25.3 \pm 0.0$ & 26.2 \\
\hline 6 & 9 & 70 & 6 & $47.1 \pm 1.0$ & 49.7 \\
\hline 7 & 9 & 90 & 3.5 & $33.1 \pm 0.0$ & 32.8 \\
\hline 8 & 9 & 90 & 3.5 & $33.3 \pm 1.0$ & 32.8 \\
\hline 9 & 9 & 90 & 3.5 & $33.3 \pm 1.2$ & 32.8 \\
\hline 10 & 9 & 110 & 1 & $47.7 \pm 1.8$ & 45.1 \\
\hline 11 & 9 & 110 & 6 & $32.9 \pm 0.0$ & 31.9 \\
\hline 12 & 12 & 70 & 3.5 & $52.1 \pm 0.0$ & 53.3 \\
\hline 13 & 12 & 90 & 1 & $49.3 \pm 3.0$ & 46.9 \\
\hline 14 & 12 & 90 & 6 & $46.3 \pm 2.5$ & 42.3 \\
\hline 15 & 12 & 110 & 3.5 & $11.1 \pm 1.0$ & 15.9 \\
\hline
\end{tabular}

Analysis of variance for yield of glucosamine is presented in Table 3.

Table3. Analysis of variance for yield of glucosamine

\begin{tabular}{|l|l|l|l|l|l|}
\hline Source & DF & Adj SS & Adj MS & F & P \\
\hline Regression & 9 & 2489.93 & 276.66 & 12.72 & 0.006 \\
\hline Linear & 3 & 348.00 & 116.00 & 5.33 & 0.051 \\
\hline Square & 3 & 269.54 & 89.85 & 4.13 & 0.08 \\
\hline Interaction & 3 & 1872.38 & 624.13 & 28.69 & 0.001 \\
\hline Pure Error & 15 & 0.59 & 0.30 & & \\
\hline
\end{tabular}

$R$ square $=95.81 \%, s=4.66399, R$ square $(\operatorname{Adj})=88.28 \%$

$R^{2}=95.8 \%$ indicates good prediction of model for experimental runs, and the value of adjusted $R^{2}$ imply that about $88.3 \%$ of experimental results can be explained by the model.

In Table 4, analysis of variance and estimated regression coefficients for polynomial model are presented.

Table4. Analysis of variance and estimated regression coefficients for polynomial model

\begin{tabular}{|l|l|l|l|l|}
\hline Term & Coefficient & SE Coefficient & T & P \\
\hline Constant & 32.89 & 2.69 & 12.21 & 0.000 \\
\hline Concentration & 6.07 & 1.65 & 3.68 & 0.014 \\
\hline Temperature & 0.27 & 1.65 & 0.16 & 0.877 \\
\hline Time & 2.57 & 1.65 & 1.56 & 0.18 \\
\hline Concentration $\times$ Concentration & -1.96 & 2.43 & -0.81 & 0.457 \\
\hline Temperature $\times$ Temperature & -2.31 & 2.43 & -0.95 & 0.386 \\
\hline Time $\times$ Time & 7.68 & 2.43 & 3.17 & 0.025 \\
\hline Concentration $\times$ Temperature & -18.99 & 2.33 & -8.14 & 0.000 \\
\hline Concentration $\times$ Time & -4.86 & 2.33 & -2.08 & 0.092 \\
\hline Temperature $\times$ Time & -9.16 & 2.33 & -3.93 & 0.011 \\
\hline
\end{tabular}

The following model was fitted to describe the effect of reaction conditions on yield of glucosamine (y):

$$
\begin{aligned}
y=-373.8+ & \left(36.69 X_{1}\right)+\left(4.54 X_{2}\right)+\left(14.75 X_{3}\right)-\left(0.218 X_{1}{ }^{2}\right)-\left(0.00576 X_{2}{ }^{2}\right) \\
& +\left(1.229 X_{3}{ }^{2}\right)-\left(0.3165 X_{1} X_{2}\right)-\left(0.648 X_{1} X_{3}\right)-\left(0.1833 X_{2} X_{3}\right)
\end{aligned}
$$

Where $\mathrm{X}_{1}, \mathrm{X}_{2}$, and $\mathrm{X}_{3}$ are acid concentration, temperature, and reaction time at their actual quantities.

Table 4 shows that acid concentration has significant effect on the yield of glucosamine $(P \ll 0.05)$. Additionally, there are significant quadratic effects between the reaction temperature and reaction time as well as concentration and the reaction temperature such that glucosamine yield decreased by increasing of these parameters. 
The optimum yield was achieved by using concentrated hydrochloric acid $(12 \mathrm{M})$ at $70{ }^{\circ} \mathrm{C}$ for $3.5 \mathrm{~h}$. Similarly, milder acidic condition $(6 \mathrm{M})$ at $110^{\circ} \mathrm{C}$ for $6 \mathrm{~h}$ also resulted in the highest yield. The highest glucosamine yield was $0.52 \mathrm{~g} / \mathrm{g}$ PFAIM, which corresponds to $90.7 \%$ of the maximum glucosamine yield that can be obtained from the available chitin and chitosan in PFAIM.

The surface plots of glucosamine yield for each pair of factors is shown in Figure 4. The highest glucosamine yield was predicted at $12 \mathrm{M}$ acid and $70-90^{\circ} \mathrm{C}$. The increasing of the reaction temperature to above $90^{\circ} \mathrm{C}$ resulted in decreasing the yield of glucosamine. In contrast, for acid concentration less than $9 \mathrm{M}$, the yield was increased even until $110^{\circ} \mathrm{C}$. At acid concentrations higher than 10M, the glucosamine was produced rapidly (Figure 4A). This is in agreement with Einbu et al. (Einbu 2007) that in concentrated acids, the depolymerization rate is higher than deacetylation rate. At this harsh condition for longer reaction times, the yield of glucosamine was rapidly decreased due to destruction and side reactions (Mojarrad and Nemati 2007).

Figure4B represents effects of acid concentration and temperature on yield of glucosamine within $6 \mathrm{~h}$. The destructive effect duo to harsh conditions existed for acid concentration higher than $9 \mathrm{M}$ and the reaction temperature above $90^{\circ} \mathrm{C}$. The negative effects may be because of glucosamine destruction in such harsh conditions, that also was reported by several authors for shellfish chitin and chitosan (Mojarrad and Nemati 2007; Yan and Evenocheck 2012).

Figure $4 \mathrm{C}$ shows that at $70^{\circ} \mathrm{C}$, the suitable acid concentration and reaction time for glucosamine preparation is about $10-12 \mathrm{M}$ and $6 \mathrm{~h}$, respectively. At temperatures lower than $90^{\circ} \mathrm{C}$, the rate of destruction was lower even at high acid concentrations. This is in agreement with Yan et al. (Yan and Evenocheck 2012)that atmild temperatures, the glucosamine destruction at high acid concentration is lower. According to Figure4D, by increasing the temperature to $110^{\circ} \mathrm{C}$, the yield of glucosamine decreased and the suitable concentration shifted to below 9M. At this condition, the appropriate reaction time to get a high glucosamine yield was $5 \mathrm{~h}$.

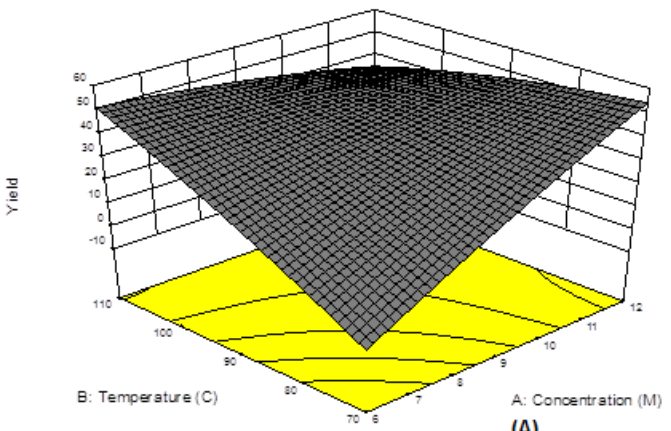

(A)

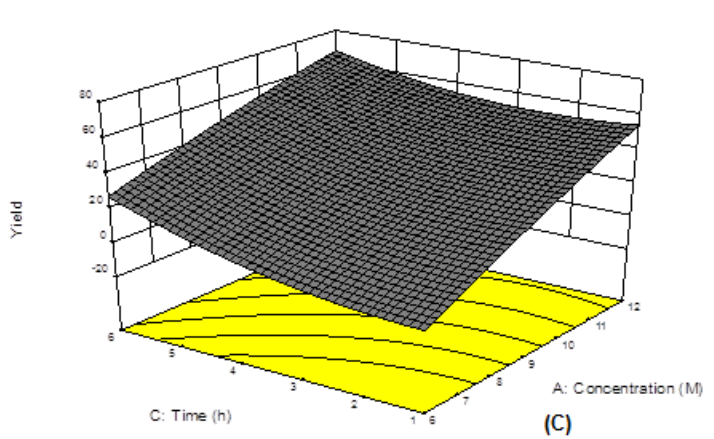

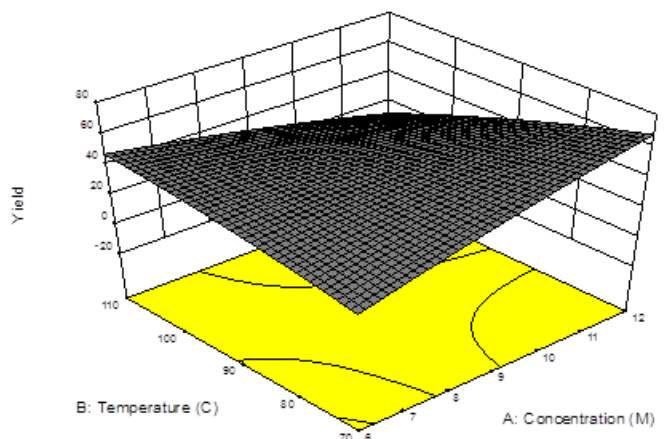

(B)

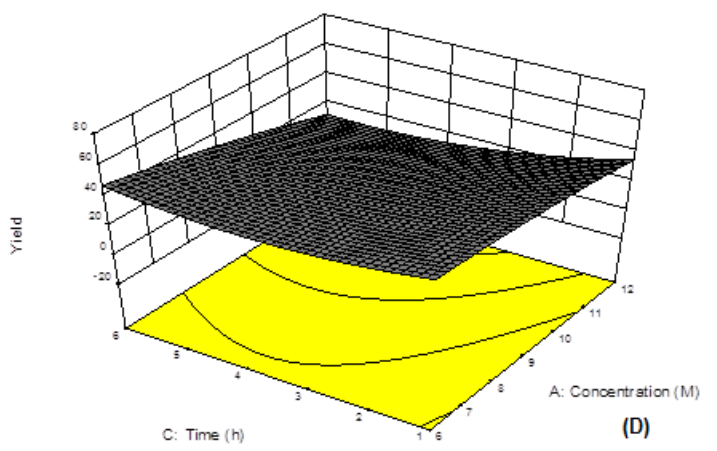

Figure4. Surface plots for the effects of temperature and concentration after $1 h(A)$, temperature and concentration after $6 \mathrm{~h}(\mathrm{~B})$, time and concentration at $70^{\circ} \mathrm{C}(\mathrm{C})$, and time and concentration at $110{ }^{\circ} \mathrm{C}(D)$

\section{Conclusions}

Glucosamine was prepared, purified, and optimized for the first time from cell wall of $R$. oryzae, a zygomycetes fungus containing chitin and chitosan. Acid concentration and the interactions between reaction temperature and reaction time as well as acid concentration and reaction temperature were effective parameters on glucosamine yield. The highest yield of glucosamine $(0.52 \mathrm{~g} / \mathrm{g}$ FPAIM) was achieved using $6 \mathrm{M}$ acid at $110^{\circ} \mathrm{C}$ and $6 \mathrm{~h}$, and also using $12 \mathrm{M}$ acid concentration at $70{ }^{\circ} \mathrm{C}$ and $3.5 \mathrm{~h}$, which represent $90.7 \%$ of theoretical yield. 


\section{ACKNOWLEDGMENTS}

The authors are grateful from Prof. Lars Edebo for providing the fungal biomass used in this research. The work was financed by Swedish Centre for Recourse Recovery, University of Borås and Institute of Biotechnology and Bioengineering, Isfahan University of Technology.

\section{Author CONTRIButions}

MS performed the experimental work drafted the manuscript under supervision of $\mathrm{AZ}$ and $\mathrm{KK}$.

\section{REFERENCES}

Abdou ES, Nagy KS, Elsabee MZ (2008) Extraction and characterization of chitin and chitosan from local sources Bioresource Technology 99:1359-1367

Ajavakom A, Supsvetson S, Somboot A, Sukwattanasinitt M (2012) Products from microwave and ultrasonic wave assisted acid hydrolysis of chitin Carbohydrate polymers 90:73-77 doi:10.1016/j.carbpol.2012.04.064

Asamoah R (2008) Determination of glucosamine in drug formulation.

Bohlmann J et al. (2004) N-acetyl-D-glucosamine and process for producing N-acetyl-D-glucosamine

Cao L, Jiang Y, Yu Y, Wei X, Li W (2008) Method for producing glucosamine from microbial biomass: 11

Dolgopyatova NV, Novikov VY, Konovalova IN (2011) Influence of the degree of deacetylation on the rate of acid degradation of chitin and chitosan and on the yield of D-glucosamine hydrochloride Russian Journal of Applied Chemistry 84:1826-1829

Edebo L (2003) Cultivation of Zygomycets from spent sulfite liquor

Einbu A (2007) Characterisation of chitin and a study of its acid-catalysed hydrolysis $\mathrm{PhD}$ diss, Norwegian University of Science and Technology, Trondheim

Flocco CG, Giulietti AM (2003) Effect of chitosan on peroxidase activity and isoenzyme profile in hairy root cultures of Armoracia lapathifolia Applied biochemistry and biotechnology 110:175183

Hsieh J-W, Wu H-S, Wei Y-H, Wang SS (2007) Determination and kinetics of producing glucosamine using fungi. Biotechnology progress 23:1009-1016 doi:10.1021/bp070037o

Islam M, Masum S (2011) Preparation of Glucosamine Hydrochloride from Indigenous Shrimp Processing Waste Bangladesh journal of scientific and industrial research 46:375-378

Karimi K, Brandberg T, Edebo L, Taherzadeh MJ (2005) Fed-batch cultivation of Mucor indicus in dilute-acid lignocellulosic hydrolyzate for ethanol production Biotechnology letters 27:13951400

Karimi K, Zamani A (2013) Mucor indicus: Biology and industrial application perspectives: A review Biotechnology advances 31:466-481

Kim WJ, Lee WG, Theodore K, Chang HN (2001) Optimization of culture conditions and continuous production of chitosan by the fungi, Absidia coerulea Biotechnology and Bioprocess Engineering 6:6-10

Liu L, Liu Y, Shin H-d, Chen R (2013) Microbial production of glucosamine and N acetylglucosamine : advances and perspectives Applied microbiology and biotechnology:61496158 doi:10.1007/s00253-013-4995-6

Luan LQ, Ha VT, Nagasawa N, Kume T, Yoshii F, Nakanishi TM (2005) Biological effect of irradiated chitosan on plants in vitro Biotechnology and applied biochemistry 41:49-57

Manni L, Ghorbel-Bellaaj O, Jellouli K, Younes I, Nasri M (2010) Extraction and characterization of chitin, chitosan, and protein hydrolysates prepared from shrimp waste by treatment with crude protease from Bacillus cereus SV1 Applied Biochemistry and Biotechnology 162:345-357

Mohammadi M, Zamani A, Karimi K (2012) Determination of glucosamine in fungal cell walls by high-performance liquid chromatography (HPLC) Journal of agricultural and food chemistry 60:10511-10515

Mohammadi M, Zamani A, Karimi K (2013) Effect of Phosphate on Glucosamine Production by Ethanolic Fungus Mucor indicus Applied biochemistry and biotechnology 171:1465-1472 
Mojarrad J, Nemati M (2007) Preparation of glucosamine from exoskeleton of shrimp and predicting production yield by response surface methodology Journal of agricultural ... 55:2246-2250

Naghdi M, Zamani A, Karimi K (2014) A sulfuric-lactic acid process for efficient purification of fungal chitosan with intact molecular weight International journal of biological macromolecules 63:158-162

Nakamura h (2011) Application of glucosamine on human disease-Osteoarthritis Carbohydrate polymers 84:835-839

Nydert P, Dragomir A, Hjelte L (2008) Chitosan as a carrier for non $\square$ viral gene transfer in a cystic $\square$ fibrosis cell line Biotechnology and applied biochemistry 51:153-157

Pan S-k, Wu S-j, Kim J-m (2011) Preparation of glucosamine by hydrolysis of chitosan with commercial $\alpha$-amylase and glucoamylase. Journal of Zhejiang University Science B 12:931-934 doi:10.1631/jzus.B1100065

Park BK, Kim M-M (2010) Applications of chitin and its derivatives in biological medicine International journal of molecular sciences 11:5152-5164

Sibi G et al. (2013) Preparation of glucosamine hydrochloride from crustacean shell waste and it ' $\mathrm{s}$ quantitation by RP-HPLC American-Eurasian Journal of Scientific Research 8:63-67

Sitanggang A (2009) Glucosamine production using Aspergillus niger. University of Bogor

Sitanggang AB, Sophia L, Wu H-S (2012) MiniReview Aspects of glucosamine production using microorganisms International Food Research Journal 19:393-404

Sitanggang AB, Wu H-S, Wang SS (2009) Determination of fungal glucosamine using HPLC with 1napthyl isothiocyanate derivatization and microwave heating Biotechnology and Bioprocess Engineering 14:819-827

Verduyn C, Postma E, Scheffers WA, van Dijken JP (1990) Physiology of Saccharomyces Cerevisiae in Anaerobic Glucose-Limited Chemostat Culturesx Journal of general microbiology 136:395403

Xavier M (2006) Standardization of optimum conditions for the production of glucosamine hydrochloride from chitin. Cochin university of science and technology

Yaghobi N (2012) Controlling chitosan's molecular weight via multistage deacetylation Biotechnology and Bioprocess Engineering 17:812-817

Yan X, Evenocheck HM (2012) Chitosan analysis using acid hydrolysis and HPLC/UV Carbohydrate Polymers 87:1774-1778 doi:10.1016/j.carbpol.2011.09.091

Yang T-L (2011) Chitin-based materials in tissue engineering: applications in soft tissue and epithelial organ International journal of molecular sciences 12:1936-1963

Zamani A (2010) Superabsorbent polymers from the cell wall of Zygomycetes fungi.

Zamani A, Edebo L, Niklasson C, Taherzadeh MJ (2010) Temperature Shifts for Extraction and Purification of Zygomycetes Chitosan with Dilute Sulfuric Acid:2976-2987doi:10.3390/ ijms11082976

Zamani A, Jeihanipour A, Edebo L, Niklasson C, Taherzadeh MJ (2008) Determination of glucosamine and $\mathrm{N}$-Acetyl glucosamine in fungal cell walls Journal of agricultural and food Chemistry 56:8314-8318

Zhang J, Liu L, Li J, Du G, Chen J (2012) Enhanced glucosamine production by Aspergillus sp. BCRC 31742 based on the time-variant kinetics analysis of dissolved oxygen level. Bioresource technology 111:507-511 doi:10.1016/j.biortech.2012.02.063 